\title{
Back to Basics - Part 1: Are We Over Treating Ocular Hypertension and Primary Open Angle Glaucoma Patients?
}

\author{
Rashid Zia, S. A. Raja, S. Aqil
}

Pak J Ophthalmol 2019, Vol. 35, No. 1

$\mathrm{P}$ opulation explosion, availability of life saving drugs and perusal of healthier life styles is leading to rising life expectancy worldwide. This indirectly translates to increasing prevalence of open angle glaucoma ${ }^{1}$ worldwide and Pakistan is no exception to these myriad factors of population increase and related healthcare issues.

Studies have in general shown increased glaucoma severity corelating with direct and indirect costs associated with the progression of disease ${ }^{2}$. Hence there is a wide spread tendency to treat suspicious optic nerve heads, mild to moderate high intraocular pressures or even documented but non progressive glaucoma damage without comprehensive structural, visual function, local and systemic risk assessment. This has in turn led to plethora of adverse clinical, socioeconomic and financial concerns triggering chain of adversities at individual and as well as national level.

The term, "target IOP" is widely used in clinical practice. Unfortunately, it tends to steer the management of glaucoma patients solely dependant on reducing IOP to "acceptable" levels. The acceptable target range(s) for IOP are often the recommendations of large land mark clinical trials (RCT's). This however frequently leads clinicians to ignore the wood for the trees. There is an inclination towards treating the pressure rather than the patient. There is an inclination towards treating the IOP to reduce it to a magic lower value rather than fully assess the patient/ individualised needs, incorporating a holistic approach based on quality of life and patient choice(s). Clinicians in their busy clinics often forget that patients are not concerned about their IOP values, digits (decibel loss) on visual fields or colours (red disease) on OCT scans. Rather patient is only concerned about two things: (a) Am I going to lose vision? or/and (b) am I going to develop disability?

To answer these questions, clinicians are required to assess the progression of the disease and the likelihood of disability in expected life span $3,4,5$.

Assessing progression and then the rate of progression is pivotal in taking decisions regarding glaucoma management, for example, it is hard to justify addition of second line of topical ocular antihypertensive drug to a regimen when patient with intraocular pressures of $26 \mathrm{~mm} \mathrm{Hg}$ on a single ocular antihypertensive drug has not shown any evidence of structural or functional loss on trend analysis. Similarly, a patient with documented progression on visual fields or OCT may still not require further lowering of IOP if the rate of progression is unlikely to cause or worsen existing disability in the life span of terminally ill patient.

Major risk factors for glaucoma blindness are the severity of disease at presentation and life expectancy ${ }^{4,6}$. A 60 years old patient with bilateral moderate glaucomatous (structural and visual functional) damage at diagnosis has a greater risk of blindness than an 85 years old with a similar amount of damage. Similarly a young patient with mild bilateral damage is at much larger risk of disability in his life tile than an 80 years old patient with moderate unilateral disease. Thus assessing rate of progression is an integral part of glaucoma management and the measured rate is what should determine the target intraocular pressure and treatment intensity. Many 
studies have found that progression is usually linear 77 (although variable or non-linear progression modelling has been documented as well). Hence the goal of initiating or intensifying the treatment is to reduce the rate of progression to prevent disability or cause further disability. Preservation of visual function and related quality of life should be planned at a sustainable cost. The cost of treatment should be calculated in terms of inconvenience and side effects as well as financial implications for the individual and society and this requires careful evaluation marrying the 'art and science of glaucoma'.

European Glaucoma Society (EGS) guidelines state, "Quality of life is closely related to visual function. Over all, patients with early to moderate glaucoma damage have good visual function and modest reduction in quality of life (QoL), while QoL is considerably reduced with advanced visual functional loss"8. Common perception that no symptoms are experienced in the early stage of the disease typically , $10^{10}$ has been challenged in the recent studies, including one large scale epidemiological study. It has been suggested that patients with even mild unilateral visual field damage may experience reduced vision related QoL (VRQoL) even if they are unaware that they suffer from glaucoma ${ }^{11}$. For example, inferior hemifield damage shows a stronger correlation than superior damage with respect to general vision, risk of falling, eye hand coordination and mobility. While superior field is more likely to interfere with reading and near activities ${ }^{12,13}$. This decreased quality of life may also result in less engagement in the real world behaviour; significantly reduced physical activity ${ }^{9}$, restriction to home and suffering with apprehension ${ }^{14}$ and depression.

Thus when taking in consideration the rate of progression, life expectancy, local and systemic risk factors, patient preferences and effects on vision related quality of Life, it is clear that there is no single "Target IOP" level that is appropriate for every patient. The target IOP needs to be estimated separately for each eye of every patient on every visit.

The Hippocratic Oath includes the promise "Primum non nocere" i.e. as to the matter of diseases, first do no harm. Glaucoma management is complex and requires a holistic approach without bringing harm to patients by carefully identifying "Target IOP"

\section{Author's Affiliation}

Rashid Zia

Lead Ophthalmologist New Hayesbank

Ophthalmology services; Ashford Kent; Uk

Lead Ophthalmologist Beltinge Ophthalmic Services; Kent UK

Glaucoma Fellow East Kent HospitalsUniversityNHS Foundation Trust UK

Mohammad S. A. Raja

Consultant Ophthalmologist with a specialist interest in Retinal diseases and Ophthalmic imaging

Clinical Lead Ophthalmology James Paget University Hospital NHS Trust Norfolk UK

Clinical Lead EADESP (East Anglian Diabetic Eye Screening Programme)

\section{S. Aqil}

Post graduate trainee

Financial Interest: None.

Conflict of Interest: None.

\section{REFERENCES}

1. Than YC Li X, Wong TY, et al. Global prevalence of glaucoma and projections of glaucoma burden through 2040: a systemic review and meta analysis. Ophthalmology, 2014; 121: 2081-2090.

2. Schmier JK, Halpren MT, Jones ML. The economic implications of glaucoma: a literature review. Pharmacoeconomics, 2007; 25 (4): 287-308.

3. Martus $\mathbf{P}$, Strous A, Budde WM, et al. Predictive factors for progressive optic nerve damage in various types of chronic open angle glaucoma. Am J Ophthalmology, 2005; 139 (6): 999-1009.

4. Peters D Bengtsson B, Heijl A. Factors associated with life time risks of open angle glaucoma blindness. Acta ophthalmologica. 2013.

5. Foresman E, Kivea T, Vest E. Life time visual disability on open angle glaucoma and ocular hypertension. Journal of glaucoma, 2007; 16 (3): 313-9.

6. Martus $\mathbf{P}$, stroux $\mathbf{A}$, Budde $\mathbf{W M}$, et al. Predictive factors for progressive optic nerve damage in various types of chronic open angle glaucoma. Am J Ophthal. 2005; 139 (6): 999-1009.

7. Pererira ML, Kim CS, Zimmerman MB, et al. Rate and pattern of visual field decline in primary open angle glaucoma. Ophthalmology, 2002; 109 (12): 2232-40.

8. Terminology and Guidelines for Glaucoma; European Glaucoma Society; 4th Edition; Chapter 3 Treatment Principles and Options, pg 133.

9. Ramulu PY, Maul E, Hochberg C, et al. Real world assessment of physical activity in glaucoma using an accelerometer. Ophthalmology, 2012; 119: 1155-1166. 
10. Kong XM, Zhu WQ, Hong JX, Sun XH. Is glaucoma comprehension associated with psychological disturbance and vision related quality of life for patients with glaucoma? A cross-sectional study. BMJ Open, 2014.

11. Peters D, Heijl A, Brenner L, Bengston B. Visual impairment and vision-related quality of life in the early Manifest Glaucoma trial after 20 years of follow up. Acta Ophthalmol. 2015; 93: 745-752.

12. Maruta $\mathbf{H}$, Hirasawa $\mathbf{H}$, Ayoma $\mathbf{Y}$, et al. Identifying areas of the visual field important for quality of life in patients with glaucoma. Ploss One 8,e58695 10.1371/journal.pone.0058695(2013)

13. Sun $\mathbf{Y}$ linc $\mathbf{C}$, Waisbourd $\mathbf{M}$, et al. The impact of visual field clusters on performance-based measures and vision-related quality of life in patients with glaucoma. Am J Ophthalmol. 2016; 163: 45-52.

14. Kotecha A; O'Leary N, Melmonth D, Grant S, Crabb DP. The functional consequences of glaucoma for eyehand coordination. Invest Ophthalmol Vis Sci 20. 09; 50 (1): 2003-213. 